\title{
Which climatic factors limit radial growth of Qilian juniper at the upper treeline on the northeastern Tibetan Plateau?
}

\author{
ZHANG Hui ${ }^{1,2,3}$, "SHAO Xuemei ${ }^{1,4}$, ZHANG Yong ${ }^{1}$ \\ 1. Key Laboratory of Land Surface Pattern and Simulation, Institute of Geographic Sciences and Natural Re- \\ sources Research, CAS, Beijing 100101, China; \\ 2. College of Resources and Environment, Linyi University, Linyi 276005, Shandong, China; \\ 3. University of Chinese Academy of Sciences, Beijing 100101, China; \\ 4. Center for Excellence and Innovation in Tibetan Plateau Earth System Sciences, CAS, Beijing 100101, China
}

\begin{abstract}
There are differing views regarding the climatic factors that limit radial growth of Qilian juniper (Juniperus przewalskii Kom.) at the upper treelines on the northeastern Tibetan Plateau. In this study, trees from an upper treeline site in the Anyemaqen Mountains of the northeastern Tibetan Plateau were selected to present new evidence that low temperature limits the radial growth of Qilian juniper. Using a signal-free regional curve standardization (SF-RCS) method, a ring-width chronology for Qilian juniper was developed extending from AD 1082 to 2010. The results of correlation analysis between tree-ring index and instrumental climatic variables showed that both winter (December in the previous year and January in the current year) and summer (July and August in the current year) temperatures were significantly and positively correlated with the tree-ring index. Precipitation in June was also significantly and positively correlated with the tree-ring index, but was not as important as low temperature in controlling tree growth. To test the key limiting climatic factor for tree radial growth at different altitudes, an indicator termed the "relative distance to upper treeline" (RDUT) was developed to quantify the representativeness of collected samples for the forest's upper treeline. The RDUT showed that the upper $20 \%$ of the forest belt may be an important boundary in terms of capturing the temperature signal from tree-ring width at the upper treelines on the northeastern Tibetan Plateau. Our findings enhance the existing understanding that temperature is the limiting factor at upper treelines on the northeastern Tibetan Plateau, and will be useful in the reconstruction of past temperature in future studies.
\end{abstract}

Keywords: Qilian juniper; climatic limiting factor; upper treeline; Tibetan Plateau; tree-ring width

\section{Introduction}

Qilian juniper (Juniperus przewalskii Kom.) is one of the most important tree species for dendroclimatology in terms of its longevity (over 2000 years) and well-preserved sub-fossil

Received: 2015-03-12 Accepted: 2015-05-05

Foundation: The Strategic Priority Research Program from the Chinese Academy of Sciences No.XDA05080201; National Natural Science Foundation of China, No.41071061

Author: Zhang Hui (1980-), PhD, specialized in dendroclimatology. E-mail: zhanghui.09b@igsnrr.ac.cn

*Corresponding author: Shao Xuemei (1957-), Professor, specialized in dendrochronology and dendroclimatology.

E-mail: shaoxm@igsnrr.ac.cn 
materials on the northeastern Tibetan Plateau (Shao et al., 2010; Sheppard et al, 2004). Since the 1970s, many dendroclimatologists have used tree-ring widths to reconstruct the history of air temperature and drought over the past millennia (Kang et al., 1997; Liu et al., 2009; Yang et al., 2014; Zhang et al., 2003). In such studies, it is crucial to determine which factors limit the radial growth of Qilian juniper to ensure accurate climate reconstructions.

Although there is consensus regarding the limits on Qilian juniper growth imposed by drought at lower and middle altitudes (Li et al., 2008; Shao et al., 2010; Shao et al., 2005), there is still uncertainty regarding the climatic factors that limit growth at the upper treelines. For example, some studies in the east Qaidam Basin (Zheng et al., 2009; Zhu et al., 2008) found that low temperature is the main limiting factor for upper treelines of Qilian juniper. In contrast, other studies in the Qaidam Basin (Liu Yu et al., 2006; Qin et al., 2013) reported that drought was the main limiting factor on tree growth at upper treelines, which is similar to the results at lower altitudes. Similar findings were also reported for Qilian juniper in other areas besides Qaidam, such as the Anyemaqen Mountains (Peng et al., 2008) and Qilian Mountains (Gou et al., 2012, Liu et al., 2005; Yang et al., 2013; Zhang et al., 2014). The lack of consensus regarding growth limitations may reflect our lack of knowledge regarding the representativeness of the samples to the upper treelines, since researchers usually take samples from an elevation range below the treeline.

The purposes of this study were: (1) to present new evidence that low temperatures limit the radial growth of Qilian juniper at an upper treeline site in the Anyemaqen area, an elevation much higher than that in a previous study; and (2) to develop an indicator with which to investigate whether the samples of the upper treelines in previous studies have the similar representativeness, given the lack of consensus in previous results. In this paper we first describe the new data from the Anyemaqen area, and then present an indicator which can be used to quantify the representativeness of a sampling site to the upper treeline. Finally, we compare the representativeness of sampling sites from different studies. The present results could provide a reference for dendroclimatologists to determine the altitude range for collecting tree-ring samples according to their reconstruction targets.

\section{Materials and methods}

\subsection{Study area}

The Anyemaqen Mountains $\left(98^{\circ} 50^{\prime}-\right.$ $102^{\circ} 25^{\prime} \mathrm{E}, 33^{\circ} 25^{\prime}-35^{\circ} 20^{\prime} \mathrm{N}$ ) extend $400 \mathrm{~km}$ from southeast to northwest and are $50-100 \mathrm{~km}$ wide (Figure 1). The mean altitude in the mountains is $>4600 \mathrm{~m}$ above sea level (a.s.l.), increasing from lower altitudes in the southeast to higher in the northwest. The climate is characterized by warm, mild summers and cold, dry winters that are typical of

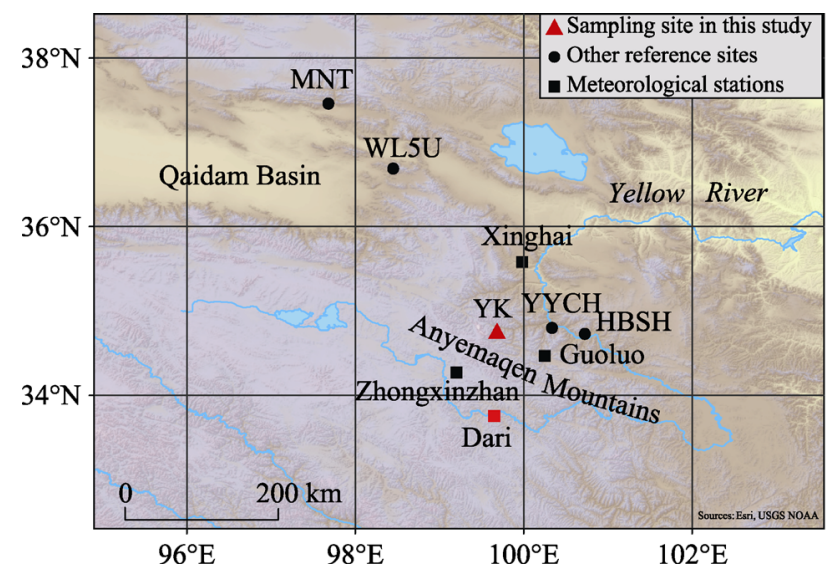

Figure 1 Location of the study site (red triangle), meteorological stations (black squares), and other reference sites (black circles). The red square is the meteorological station whose data was used in this study 
semi-humid and semi-arid climates (Zheng et al., 2013) due to the influence of both the Asian monsoon and the Asian westerly (Dai, 1970). According to climate records from the surrounding meteorological stations, the mean annual temperature ranges from -4.1 to $1.3^{\circ} \mathrm{C}$, with the lowest monthly mean temperature of $-16.9^{\circ} \mathrm{C}$ occurring in January and the highest monthly mean temperature of $15.1{ }^{\circ} \mathrm{C}$ occurring in July. From southeast to northwest, the mean annual total precipitation ranges from 584 to $319 \mathrm{~mm}$, with $55.2 \%-62.4 \%$ of precipitation falling from June to August.

\subsection{Sampling, cross-dating, and chronology development}

The sampling site $\left(\mathrm{YK}, 99^{\circ} 41^{\prime} \mathrm{E}, 34^{\circ} 45^{\prime} \mathrm{N}\right.$; Figure 1) is located at Xueshan town, about 20 $\mathrm{km}$ from the highest peak of the Anyemaqen Mountains. Qilian juniper trees are found mainly on the southern and eastern slopes with open canopy. The elevation of our sampling site is close to the upper treeline of Qilian juniper in this area with an elevation of approximately $4255 \mathrm{~m}$, which is much higher than in previous studies in this area (3845 m) (Peng et al., 2008). We extracted increment cores from trees with diameters of $>20 \mathrm{~cm}$ and heights of $>2 \mathrm{~m}$ in the upper treeline ecotone with an altitude range of $\sim 4100$ to $4255 \mathrm{~m}$ a.s.l. To exclude the influence of reaction wood, cores were sampled parallel to the orientation of the mountain. In total, 129 increment cores were taken from 71 trees.

After drying, the tree-ring cores were mounted, sanded, and cross-dated according to conventional techniques (Cook and Kairiukstis, 1990; Fritts, 1976). We measured tree-ring widths using a LINTAB 6 system with a $0.01 \mathrm{~mm}$ resolution. We then used the COFECHA program to check the validity of cross-dating (Holmes, 1983). Finally, 118 cores from 64 trees were retained after excluding 11 cores due to their age being $<100$ years, or their correlation coefficients with the master series being $<0.5$.

A signal-free regional curve standardization (SF-RCS) method (Melvin and Briffa, 2014) was selected to remove potential age- and size-related trends in this study. This method could preserve more low-frequency variabilities in the raw ring-width series compared with traditional RCS (Xu and Shao, 2007), because it first estimates a so-called signal-free growth curve from age-aligned ring-width data after iteratively excluding common medium frequency variations. An age-depth method was then used to fit the estimation to obtain a smoothed series. Each raw ring-width series was divided by the smoothed series at the relevant ages to obtain a standardized index series. Finally, an arithmetic mean was selected to create a ring-width chronology. To evaluate the signal strength of the chronology, we calculated statistics such as the correlations between trees, the correlations within trees, the signal-to-noise ratio (SNR), and the expressed population signal (EPS) (Cook and Kairiukstis, 1990; Fritts, 1976) in the common interval (AD 1801-2000).

\subsection{Tree-ring-climate relationship}

To investigate the relationship between the radial growth of trees and climatic factors, we calculated Pearson correlation coefficients between the ring-width chronology and climate variables including the monthly mean temperature, monthly mean maximum temperature, monthly mean minimum temperature, and total monthly precipitation. We also calculated correlation coefficients after all of the data were first differenced to evaluate their relation- 
ships at high frequency. Four meteorological stations are around our study area (Xinghai, Dari, Zhongxinzhan and Guoluo stations; Figure 1). The Zhongxinzhan and Guoluo stations are closer to the sampling sites (within 60-70 km); however, the Zhongxinzhan station record ended in 1997 and the Guoluo record only started in 1991. Xinghai station $\left(99^{\circ} 59^{\prime} \mathrm{E}\right.$,

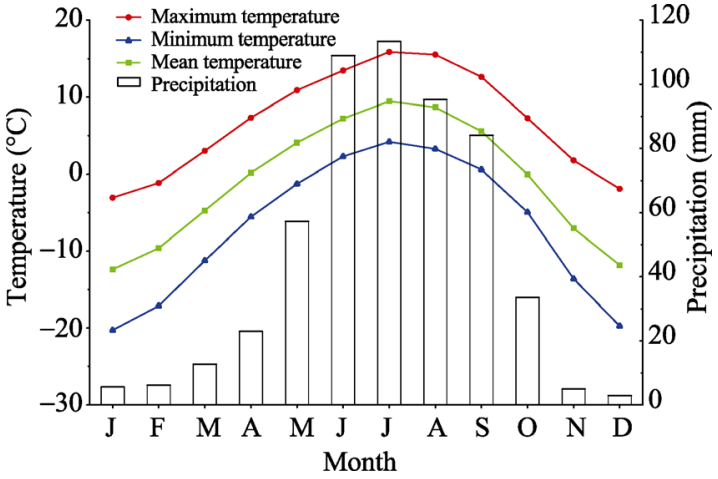

Figure 2 Monthly mean, maximum, and minimum temperatures, and precipitation at the Dari meteorological station, 1956-2010 $35^{\circ} 35^{\prime} \mathrm{N}$ ) is located $99 \mathrm{~km}$ northeast of sampling site, but the elevation of Xinghai station (3323.2 $\mathrm{m}$ a.s.1) much lower than that of our tree-ring site $(>4100 \mathrm{~m}$ a.s.l). Dari station $\left(99^{\circ} 39^{\prime} \mathrm{E}, 33^{\circ} 45^{\prime} \mathrm{N}\right)$ is located in $110 \mathrm{~km}$ south of the sampling site with more than 50 years of instrumental data, its elevation (3967.5 $\mathrm{m}$ a.s.1) is similar to that of our site. The Dari station data strongly correlate with that from the Zhongxinzhan and Guoluo stations during common periods. Accordingly, climate data from the Dari meteorological station (1956-2010) was used here (Figure 2).

\subsection{Representativeness of sampled trees}

We developed an indicator termed the Relative Distance to Upper Treeline (RDUT) to quantify the degree to which the collected samples are representative of the upper treeline of the forest, as follows:

$$
\mathrm{RDUT}=\frac{H_{u}-h}{H_{u}-H_{l}}
$$

where $h$ is the altitude of the sampled tree, $H_{u}$ is the altitude of the upper treeline, and $H_{l}$ is the altitude of the lower treeline. If the value of RDUT is zero, the sample is from the upper treeline. The largest value of RDUT is 1 , indicates a sample from the lower treeline. The larger the RDUT, the poorer the representativeness of the sample to the upper treeline of the forest. Equation (1) applies to a single sampled tree. For a site, we use the average of the RDUT (ARDUT) of $n$ sampled trees:

$$
\text { ARDUT }=\frac{\sum_{i=1}^{n} \frac{H_{u}-h_{l}}{H_{u}-H_{l}}}{n}
$$

Because not all earlier studies on Qilian juniper provide detailed location information for each sampled tree, we could not calculate the ARDUT for these cases. Fortunately, some of the studies provided the altitude range of their sampled trees. Hence, we calculated the upper and lower-boundary RDUT values to assess the representativeness of samples using Equation (1). This included both the temperature- and drought-sensitive sites of published studies (Table 1). For each sampling site, we first located the upper and lower treelines on Google Earth, which shows very high-resolution images on which we could easily identify forests at the sites. We then determined the elevations of the upper and lower treelines from a Digital Elevation Model (DEM). For the HBSH site (Peng et al., 2008) the authors only provided 
the elevation of the site. This elevation was assumed to represent the lower sampling boundary, and the elevation of the trees at the top of the slope (3790 $\mathrm{m}$ a.s.l.) was assumed to represent the upper sampling boundary. These assumptions ensure that there is no underestimation of the elevations of the actual lower and upper sampling boundaries.

\section{Results}

\subsection{Statistics of the new tree-ring chronology for Anyemaqen}

The tree-ring width chronology started from AD 1073 and from AD 1405 with EPS $>0.85$ (Figure 3). The chronology has a mean sensitivity of 0.17 and a first-order autocorrelation coefficient of 0.55 . The signal-to-noise ratio is 16.79 and the expressed population signal is 0.95 in the common interval. The correlation coefficients between and within trees are 0.20 and 0.65 , respectively.

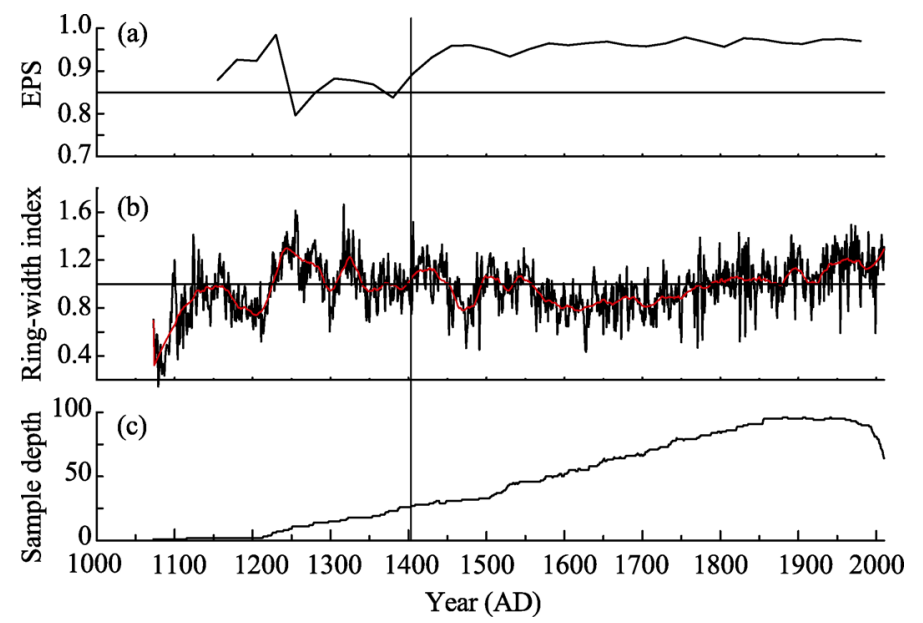

Figure 3 SF-RCS tree-ring width chronology of Qilian juniper at Yangkao (YK). (a) 50-year running expressed population signal (EPS), (b) ring-width chronology with a 50-year moving average (red line), and (c) sample depth of the chronology

\subsection{Correlations between tree-ring chronology and climate data}

Figures $4 \mathrm{a}$ and $4 \mathrm{c}$ show the correlation coefficients between the tree-ring index and climate data. Most of the correlations of tree-ring index with temperature are positive, with the exception of April and May (Figure 4a). The tree-ring index significantly correlated with both pre-growth winter temperatures (prior December to current March) and summer temperatures (current July to current August). The highest correlation coefficient $(r=0.486)$, was found for the July-August mean maximum temperature. There were fewer positive correlations between the chronology and precipitation (Figure 4c). Correlation with May-June precipitation $(r=0.316)$ was the strongest, but was much weaker than correlations with temperature, such as for July-August in the current year and prior October-current March.

The correlations with precipitation (Figure 4d) after all of the data were first differenced were also lower than those with temperature (Figure 4b). For example, the highest positive correlation with precipitation ( $r=0.376$ ) was in late spring and early summer (May-June). 
Stronger significant correlations with temperature were found in July-August $(r=0.417)$ and October-March $(\mathrm{r}=0.525)$. In addition, temperature in May showed a significant negative correlation with the chronology.
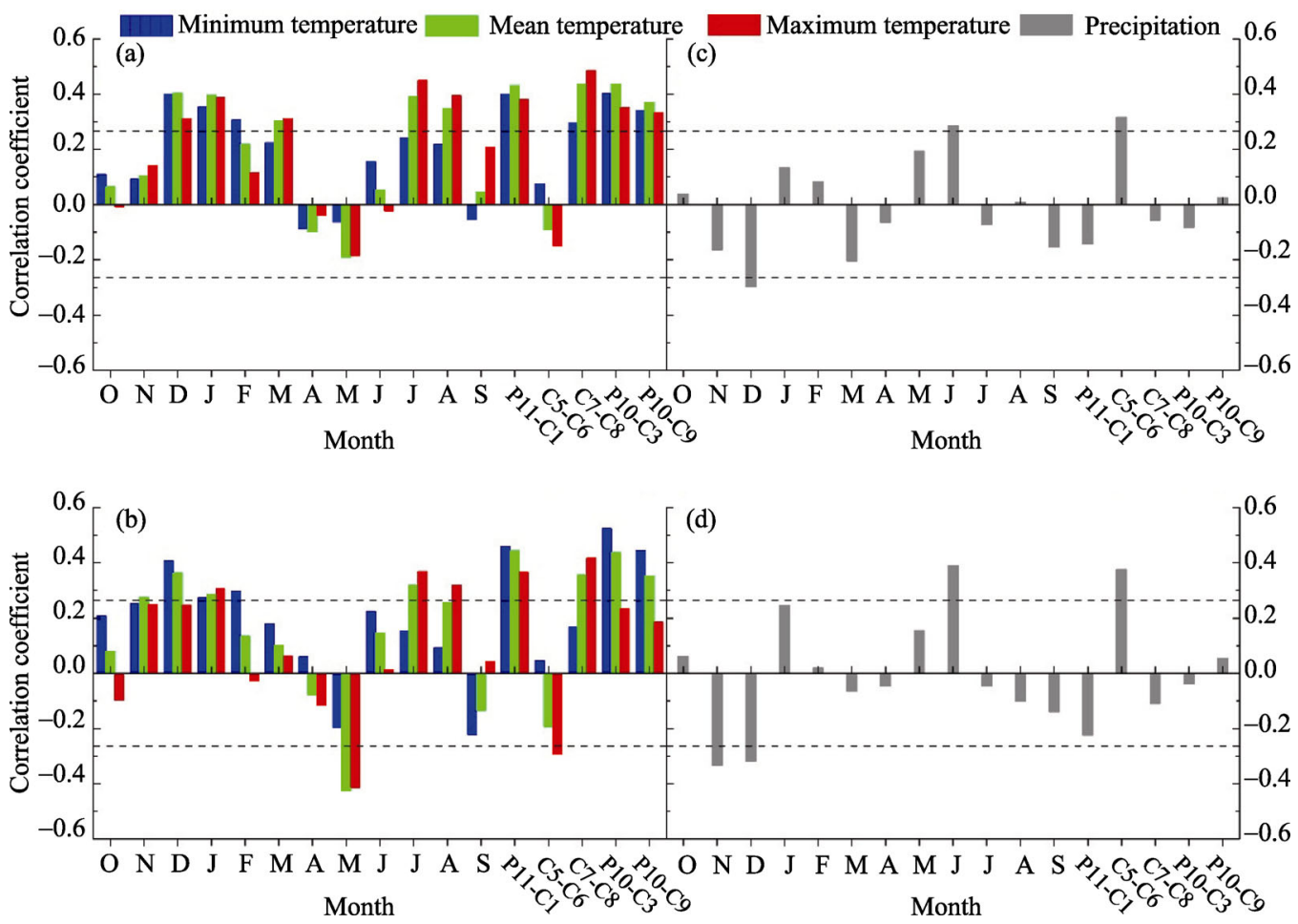

Figure 4 The correlations ( $a, c)$ and first-order correlations (b, d) between ring-width chronology and climate variables at Dari meteorological station from October in the previous year to September in the current year and seasonally assembled, using data from 1956 to 2010. The horizontal dashed lines indicate the 95\% confidence intervals for the correlation coefficients. P11-C1: previous November to current January, C5-C6: current May and June, C7-C8: current July and August, P10-C3: previous October to current March, P10-C3: previous October to current September.

\subsection{Representativeness of sampling sites in related studies}

Table 1 lists the RDUT values of sampling sites for upper treelines of Qilian juniper in this and previous studies. In the temperature-sensitive group, all of the $\mathrm{RDUT}_{u}$ (RDUT of the upper sampling boundary) values are $<0.10$, indicating that the upper sampling boundary

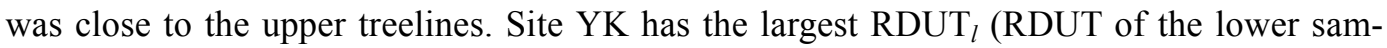
pling boundary) value, 0.21 , indicating that all of the temperature-sensitive samples were from the upper $\sim 20 \%$ of the Qilian juniper forest belt at their respective sites.

In the precipitation-sensitive group, all $\mathrm{RDUT}_{u}$ values are $>0.20$. The $\mathrm{RDUT}_{l}$ value reaches 0.42 at MNT (Qin et al., 2013). All of the $\mathrm{RDUT}_{u}$ and $\mathrm{RDUT}_{l}$ values in the precipitation-sensitive group are larger than the respective values in the temperature-sensitive group. The $\mathrm{RDUT}_{u}$ values of the precipitation-sensitive group are even larger than the $\mathrm{RDUT}_{l}$ values of the temperature-sensitive group. The upper sampling boundaries (UBE) at MNT and HBSH were at least $130 \mathrm{~m}$ lower than the relevant upper treelines; this indicates that the samples were all taken below the upper $\sim 20 \%$ of the forest belt. 
Table 1 The relative distance to upper treeline (RDUT) of the tree-ring sites

\begin{tabular}{ccccccccccc}
\hline \multirow{2}{*}{$\mathrm{LCF}^{1}$} & Site & Latitude & Longitude & $\mathrm{UBE}^{2}$ & $\mathrm{LBE}^{2}$ & $\mathrm{UTE}^{3}$ & $\mathrm{LTE}^{3}$ & $\mathrm{RDUT}_{l}^{4}$ & $\mathrm{RDUT}_{u}^{4}$ & Data source \\
\hline \multirow{5}{*}{ Temperature } & $\mathrm{YK}$ & $34^{\circ} 45^{\prime} 51^{\prime \prime}$ & $99^{\circ} 40^{\prime} 59^{\prime \prime}$ & 4255 & 4100 & 4255 & 3500 & 0.21 & 0.00 & This study \\
& $\mathrm{YYCH}$ & $34^{\circ} 48^{\prime} 01^{\prime \prime}$ & $100^{\circ} 20^{\prime} 10^{\prime \prime}$ & 3845 & 3750 & 3845 & 3350 & 0.19 & 0.00 & Peng et al. (2008) \\
& $\mathrm{WL2U}$ & $37^{\circ} 02^{\prime} 47^{\prime \prime}$ & $98^{\circ} 39^{\prime} 49^{\prime \prime}$ & 3964 & 3910 & 4010 & 3430 & 0.17 & 0.08 & Zhu et al. (2008) \\
\hline \multirow{2}{*}{ Precipitation } & $\mathrm{MNT}$ & $37^{\circ} 31^{\prime} 03^{\prime \prime}$ & $97^{\circ} 02^{\prime} 46^{\prime \prime}$ & 4015 & 3900 & 4150 & 3550 & 0.42 & 0.22 & Qin et al. (2013) \\
& $\mathrm{HBSH}$ & $34^{\circ} 43^{\prime} 32^{\prime \prime}$ & $100^{\circ} 43^{\prime} 33^{\prime \prime}$ & 3790 & 3700 & 4000 & 3300 & 0.39 & 0.30 & Peng et al. (2008) \\
\hline
\end{tabular}

*Elevation data are given in meters above sea level.

1. LCF: limiting climatic factor

2. UBE: upper boundary elevation of sampling, LBE: lower boundary elevation of sampling

3. UTE: upper treeline elevation, LTE: lower treeline elevation

4. $\mathrm{RDUT}_{l}$ : relative distance to upper treeline of the lower sampling boundary, $\mathrm{RDUT}_{u}$ : relative distance to upper treeline of the upper sampling boundary

\section{Discussion}

\subsection{Growth response of Qilian juniper to climatic factors in the Anyemaqen region}

The results of correlation analysis indicate that both summer temperature and pre-growth winter temperature have the strongest influence on tree growth at the upper treeline. This is consistent with earlier findings for the upper treelines of the same area (Peng et al., 2008), the east Qaidam Basin (Zheng et al., 2009; Zhu et al., 2008), and the Qilian Mountains (Zhang et al., 2014). A warmer growing season is likely to favor photosynthesis, cell division, and substantial accumulation in the trees, thus producing wider growth rings (Fritts, 1976). An effect of winter temperature on tree growth has also been reported in Nepal (Cook et al., 2003), North America (Pederson et al., 2004), west Sichuan (Shao and Fan, 1999), and the Changbai Mountains in northeast China (Zhu et al., 2009). Higher winter temperatures will limit the damage of the frost or freezing to the leaves or roots of trees, which subsequently affects tree growth in the coming year (Grace and Norton, 1990; Kullman, 2014; Payette et al., 1996; Toromani et al., 2011). Therefore, temperature plays a more important role than precipitation in the growth of Qilian juniper at the upper treeline in our study area.

It appears that drought in late spring and early summer also affects tree growth at the Anyemaqen study site. This effect has been verified by recent monitoring of the xylogenesis of Qilian juniper in Dulan (Ren et al., 2015), which showed that precipitation in June triggers the onset of xylogenesis. In addition, high temperature in May leads considerable evaporation from the soil and transpiration from leaves, causing drought stress on cambial activity. However, the influence of drought is not as strong as that reported in other studies at lower elevations (Gou et al., 2014; Liu Lusan et al., 2006; Shao et al., 2005; Zhang et al., 2003), suggesting that more soil moisture is available at high elevations due to lower evaporation and higher precipitation. Thus, the moisture-triggered onset of cell division could only play a weaker role than low temperature in controlling the whole ring width of Qilian juniper at the upper treeline.

\subsection{Representativeness of sampling in related studies}

The obvious differences in RDUT values between the present and previous studies suggest 
the low representativeness of samples for upper treelines may be the reason for the contrasting findings regarding the factors limiting radial growth of Qilian juniper on the northeast Tibetan Plateau. The poor representativeness can be ascribed to the inclusion of trees from relatively low altitudes in the forest belt. Because HBSH (Peng et al., 2008) and MNT (Qin et al., 2013) reported similar drought-response patterns to those of other lower-elevation tree-ring sites (Gou et al., 2007; Liu Yu et al., 2006; Qin et al., 2013; Shao et al., 2005; Zhang et al., 2003), it is reasonable to infer that trees with $\mathrm{RDUT}_{u}>0.4$ are sensitive to drought stress. Tree growth is sensitive to temperature if $\mathrm{RDUT}_{u}<0.08$, as indicated by the upper sampling boundary of WL2U (Zhu et al., 2008).

The RDUT $T_{l}$ values of lower samplings boundaries indicate that the upper $20 \%$ of the forest belt is an important line dividing between different climate-growth relationships for Qilian juniper on the northeastern Tibetan Plateau, which is within about 100-150 m of the upper treelines in our study. In the arid western USA, tree growth is only limited by temperature within $\sim 150 \mathrm{~m}$ of the upper treeline (Salzer et al., 2009). However, the dividing line between different climate-growth relationships may vary with local climatic conditions. For example, the radial growth of Smith fir is limited by low temperature at altitudes of 3550-4390 m a.s.1. in the Sygera Mountains in the moist southeast Tibetan Plateau (Liang et al., 2010). If there is a decreasing trend in precipitation along this altitude gradient, the trees with lower RDUT values may also be limited by moisture (Liang et al., 2014; Morales et al., 2004). Therefore, caution should be taken to use the RDUT values in this study as references for areas with very different climate conditions.

\section{Conclusions}

This study developed a 938-year ring-width chronology using a SF-RCS method and analyzed the factors limiting Qilian juniper growth at the upper treelines on the northeastern Tibetan Plateau. The correlations between the climate factors and tree-ring index showed the tree-ring index significantly correlated with both pre-growth winter temperatures and summer temperatures. Precipitation in June was also significantly and positively correlated with the tree-ring index. A warmer growing season is likely to favor photosynthesis, cell division, and substantial accumulation in the trees, thus producing wider growth rings. Higher winter temperatures will limit the damage of the frost or freezing to the leaves or roots of trees, which subsequently affects tree growth in the coming year. High temperature in May would lead considerable evaporation from the soil and transpiration from leaves, causing drought stress on cambial activity. However, precipitation is not as important as the temperature in controlling tree's radial growth, the moisture-triggered onset of cell division in late spring and early summer could only play a weaker role than low temperature in controlling the whole ring width of Qilian juniper at the upper treelines.

Our results support the notion that low temperature, both in summer and pre-growth winter, is the main climatic factor limiting Qilian juniper growth at the upper treeline. However, the literature contains inconsistent conclusions on this point on the northeastern Tibetan Plateau, so we developed the RDUT to quantify the representativeness of the collected samples for a forest's upper treeline. Our limited data showed that the samples in the temperature-sensitive group were all collected above the upper $20 \%$ of the forest belt, and the sam- 
ples in the precipitation-sensitive group were all collected below the upper $20 \%$ of the forest belt. A RDUT value $<0.20$ may be appropriate for capturing temperature signals in tree-ring widths in the present study area. The low degree to which the sampling sites in some previous studies are representative of the actual upper treeline, owing to the inclusion of trees from too-low elevations, may have led to the misunderstanding that drought is the main growth limiting factor. Therefore, when temperature series is going to be reconstructed from tree rings on the northeastern Tibetan Plateau, it is necessary to first determine a reasonable sampling range based on a detailed elevation survey of the forest belt.

\section{References}

Cook Edward, Kairiukstis L, 1990. Methods of Dendrochronology: Applications in the Environmental Sciences. Dororechit, Holland: Kluwer Academic Publishiers.

Cook Edward, Krusic Paul, Philip Jones, 2003. Dendroclimatic signals in long tree-ring chronologies from the Himalayas of Nepal. International Journal of Climatology, 23(7): 707-732.

Dai Jiaxi, 1970. The Climate of the Tibetan Plateau. Beijing: China Meteorological Press. (in Chinese)

Fritts Harold, 1976. Tree Rings and Climate. London: Academic Press.

Gou Xiaohua, Chen Fahu, Cook Edward, 2007. Streamflow variations of the Yellow River over the past 593 years in western China reconstructed from tree rings. Water Resources Research, 43(6): W06434.

Gou Xiaohua, Gao Linlin, Deng Yang, 2014. An 850-year tree-ring-based reconstruction of drought history in the western Qilian Mountains of northwestern China. International Journal of Climatology. doi: 10.1002/joc.4208.

Gou Xiaohua, Zhang Fen, Deng Yang, 2012. Patterns and dynamics of tree-line response to climate change in the eastern Qilian Mountains, northwestern China. Dendrochronologia, 30(2): 121-126.

Grace J, Norton DA, 1990. Climate and growth of Pinus sylvestris at its upper altitudinal limit in Scotland: Evidence from tree growth-rings. Journal of Ecology, 78(3): 601-610.

Holmes Richard, 1983. Computer-assisted quality control in tree-ring dating and measurement. Tree-Ring Bulletin, 43: 69-78.

Kang Xingcheng, Graumlich Lisa, Sheppard Paul, 1997. A 1835 a tree-ring chronology and its preliminary analyses in Dulan region, Qinghai. Chinese Science Bulletin, 42(13): 1122-1124.

Kullman Leif, 2014. Treeline (Pinus sylvestris) landscape evolution in the Swedish Scandes: A 40-year demographic effort viewed in a broader temporal context. Norsk Geografisk Tidsskrft-Norwegian Jounal of Geography, 68(3): 155-167.

Li Jingbao, Cook Edward, D'Arrigo Rosanne, 2008. Common tree growth anomalies over the northeastern Tibetan Plateau during the last six centuries: Implications for regional moisture change. Global Change Biology, 14(9): 2096-2107.

Liang Eryuan, Dawadi Binod, Pederson Neil, 2014. Is the growth of birch at the upper timberline in the Himalayas limited by moisture or by temperature? Ecology, 95(9): 2453-2465.

Liang Eryuan, Wang Yafeng, Xu Yan, 2010. Growth variation in Abies georgei var. smithii along altitudinal gradients in the Sygera Mountains, southeastern Tibetan Plateau. Trees-Structure and Function, 24(2): 363-373.

Liu Lusan, Shao Xuemei, Liang Eryuan, 2006. Climate signals from tree ring chronologies of the upper and lower treelines in the Dulan region of the northeastern Qinghai-Tibetan Plateau. Journal of Integrative Plant Biology, 48(3): 278-285.

Liu Xiaohong, Qin Dahe, Shao Xuemei, 2005. Temperature variations recovered from tree-rings in the middle Qilian Mountain over the last millennium. Science in China Series D: Earth Sciences, 48(4): 521-529.

Liu Yu, An Zhisheng, Linderholm Hans, 2009. Annual temperatures during the last 2485 years in the mid-eastern Tibetan Plateau inferred from tree rings. Science in China Series D: Earth Sciences, 52(3): 348-359.

Liu Yu, An Zhisheng, Ma Haizhou, 2006. Precipitation variation in the northeastern Tibetan Plateau recorded by the tree rings since $850 \mathrm{AD}$ and its relevance to the Northern Hemisphere temperature. Science in China Series D: Earth Sciences, 49(4): 408-420. 
Melvin Thomas, Briffa Keith, 2014. CRUST: Software for the implementation of Regional Chronology Standardisation: Part 1. Signal-Free RCS. Dendrochronologia, 32(1): 7-20.

Morales Mariano, Villalba Richrdo, Grau Richrdo, 2004. Rainfall-controlled tree growth in high-elevation subtropical treelines. Ecology, 85(11): 3080-3089.

Payette Serge, Delwaide Ann, Morneau Claude, 1996. Patterns of tree stem decline along a snow-drift gradient at treeline: A case study using stem analysis. Canadian Journal of Botany-Revue Canadienne De Botanique, 74(11): 1671-1683.

Pederson Neil, Cook Edward, Jacoby Gordon, 2004. The influence of winter temperatures on the annual radial growth of six northern range margin tree species. Dendrochronologia, 22(1): 7-29.

Peng Jianfeng, Gou Xiaohua, Chen Fahu, 2008. Difference in tree growth responses to climate at the upper treeline: Qilian juniper in the Anyemaqen Mountains. Journal of Integrative Plant Biology, 50(8): 982-990.

Qin Chun, Yang Bao, Melvin Thomas, 2013. Radial growth of Qilian juniper on the northeast Tibetan Plateau and potential climate associations. Plos One, 8(11): e79362.

Ren Ping, Rossi Sergio, Gricar Jozica, 2015. Is precipitation a trigger for the onset of xylogenesis in Juniperus przewalskii on the north-eastern Tibetan Plateau? Annals of Botany, 115(4): 629-639.

$\mathrm{Xu}$ Yan, Shao Xuemei, 2007. Standardization of Qilian Juniper ring-width series in the eastern margin of the Qaidam Basin. Journal of Geographical Sciences, 17(2): 175-186.

Salzer Matthew, Hughes Malcolm, Bunn Andrew, 2009. Recent unprecedented tree-ring growth in Bristlecone pine at the highest elevations and possible causes. Proceedings of the National Academy of Sciences of the United States of America, 106(48): 20348-20353.

Shao Xuemei, Fan Jinmei, 1999. Past Climate on west Sichuan plateau as reconstructed from ring-widths of Dragon spruce. Quateranry Sciences, 19(1): 81-89. (in Chinese)

Shao Xuemei, Huang Lei, Liu Hongbing, 2005. Reconstruction of precipitation variation from tree rings in recent 1000 years in Delingha, Qinghai. Science in China Series D: Earth Sciences, 48(7): 939-949.

Shao Xuemei, Xu Yan, Yin Zhiyong, 2010. Climatic implications of a 3585-year tree-ring width chronology from the northeastern Qinghai-Tibetan Plateau. Quaternary Science Reviews, 29(17/18): 2111-2122.

Sheppard Paul, Tarasov Pavel, Graumlich Lisa, 2004. Annual precipitation since 515 BC reconstructed from living and fossil juniper growth of northeastern Qinghai Province, China. Climate Dynamics, 23: 869-881.

Toromani Elvin, Sanxhaku Mitat, Pasho Edmond, 2011. Growth responses to climate and drought in silver fir (Abies alba) along an altitudinal gradient in southern Kosovo. Canadian Journal of Forest Research, 41(9): 1795-1807.

Yang Bao, He Minghui, Melvin Thomas, 2013. Climate control on tree growth at the upper and lower treelines: A case study in the Qilian Mountains, Tibetan Plateau. Plos One, 8(7): 1-12.

Yang Bao, Qin Chun, Wang Janglin, 2014. A 3,500-year tree-ring record of annual precipitation on the northeastern Tibetan Plateau. Proceedings of the National Academy of Sciences, 111(8): 2903-2908.

Zhang Qibing, Cheng Guodong, Yao Tandong, 2003. A 2,326-year tree-ring record of climate variability on the northeastern Qinghai-Tibetan Plateau. Geophysical Research Letters, 30(14): 1739-1741.

Zhang Yong, Shao Xuemei, Yin Zhiyong, 2014. Millennial minimum temperature variations in the Qilian Mountains, China: Evidence from tree rings. Climate of the Past, 10: 1763-1788.

Zheng Jingyun, Bian Juanjuan, Ge Quansheng, 2013. The climate regionalization in China for 1981-2010. Chinese Science Bulletin, 58(30): 3088-3099. (in Chinese)

Zheng Yonghong, Zhu Haifeng, Zhang Yongxiang, 2009. Relationships between Sabina Przewalskii radil growth and climatic factors at upper timberlines in eastern mountainous region of Qaidam Basin. Chinese Journal of Applied Ecology, 20(3): 507-512. (in Chinese)

Zhu Haifeng, Fang Xiuqi, Shao Xuemei, 2009. Tree ring-based February-April temperature reconstruction for Changbai Mountain in Northeast China and its implication for East Asian winter monsoon. Climate of the Past, 5(4): 661-666.

Zhu Haifeng, Zheng Yonghong, Shao Xuemei, 2008. Millennial temperature reconstruction based on tree-ring widths of Qilian juniper from Wulan, Qinghai Province, China. Chinese Science Bulletin, 53(24): 3914-3920. 